\title{
3D-Printed Microfluidic Nanoelectrospray Ionization Source Based on Hydrodynamic Focusing
}

\author{
Yu Zhao, ${ }^{* \dagger}$ Shichang Jiang, ${ }^{* \dagger}$ Yuna BaI, $*$ Xueying HuAng, ${ }^{*} * *$ and Bo XIONG $* * * \dagger$ \\ *Key Laboratory of Pesticides \& Chemical Biology of Ministry of Education, College of Chemistry, \\ Central China Normal University, Wuhan 430079, China \\ **Hubei International Scientific and Technological Cooperation Base of Pesticide and Green Synthesis, \\ College of Chemistry, Central China Normal University, Wuhan 430079, China
}

\begin{abstract}
Nanoelectrospray ionization (nESI) mass spectrometry (MS) is an ideal detection method for microfluidic chips, and its performances depend on nESI emitters. However, the fabrication of monolithic nESI emitters in chips was difficult. Herein, we propose a three-dimensional (3D) printing method to develop a microfluidic nanoelectrospray ionization source (NIS), composed of a nESI emitter and other components. Firstly, the NIS was compatible with a $50-500 \mathrm{~nL} \mathrm{~min}{ }^{-1}$ nanoflows by imposing 3D hydrodynamic focusing to compensate for the total flow rate, achieving a $7.2 \%$ best relative standard deviation in the total ion current (TIC) profiles. Additionally, it was applied to probe thirteen organic chemicals, insulin, and lysozyme with adequate signal-to-noise ratios and an accuracy of $\mathrm{m} / \mathrm{z}$ between $9.02 \times 10^{-1}$ and $1.48 \times 10^{3} \mathrm{ppm}$. Finally, the NIS achieved comparable limits of detection compared with its commercial counterpart. Considering the standardized preparation of NIS, it would be a potential option to develop 3D-printed customized Chip-MS platforms.
\end{abstract}

Keywords Nanoelectrospray ionization source, 3D printing, monolithic spray emitter, microfluidic hydrodynamic focusing, Chip-MS platform

(Received June 21, 2020; Accepted October 24, 2020; Advance Publication Released Online by J-STAGE October 30, 2020)

\section{Introduction}

Nanoelectrospray ionization mass spectrometry (nESI-MS) is compatible with micro- and nano-flows, ${ }^{1,2}$ and it achieves better sensitivities compared with conventional electrospray MS. ${ }^{1,3}$ It has thus been used in various applications, ${ }^{4,5}$ including on-line MS detections for microfluidic chips. ${ }^{6,7}$ The electrospray emitter is the key interface between sample flows and mass spectrometers, and it influences the ionization efficiency of nESI sources. However, a facile and standardized method to fabricate monolithic nESI emitters in microfluidic chips is still absent, ${ }^{8,9}$ although they could provide near-zero dead volume in on-line chip-MS methods.

The preparation of nESI emitters via standardized strategies has always been tough. Although poly(dimethylsiloxane $)^{6,10,11}$ and poly(methyl methacrylate $)^{12}$ emitters were reported, glass nESI emitters are the most widely applied, ${ }^{8,13}$ and they are generally prepared by chemical etching, ${ }^{14}$ heat pulling, ${ }^{15}$ or mechanical grinding. ${ }^{16,17}$ However, preceding nESI emitters are with confined configurations. ${ }^{18}$ This leads to complex and laborious preparations, ${ }^{17,19,20}$ and thus makes these emitters high-cost or fragile. These features, in turn, deteriorated the difficulties to integrate nESI emitters in microfluidic chips. ${ }^{21,22}$

Alternatively, three-dimensional (3D) printing has shown potentials to ease hurdles in preparing nESI emitters. Fused

Y. Z. and S. J. contributed equally to this work.

† To whom correspondence should be addressed.

E-mail: bx@mail.ccnu.edu.cn deposition modelling (FDM) is the most widely used 3D printing methods, ${ }^{23,24}$ and it constructs $3 \mathrm{D}$ spatial objects by deposing melted polymers in pre-specified layers. ${ }^{25,26}$ It has been used to prepare different analytical devices, ${ }^{27,28}$ including cartridges for paper-based electrospray ionization, ${ }^{25,29,30}$ the ion mobility spectrometer, ${ }^{31,32}$ the ion funnel, ${ }^{33}$ the spray chamber for inductively coupled plasma spectrometry, ${ }^{34}$ and other interfaces..$^{35,36}$ However, its spatial resolution is insufficient to directly prepare nESI emitters with an inner diameter of a few micrometres. ${ }^{1,2}$ If its resolution could be compensated, a facile and standardized FDM method would be developed to prepare nESI emitters.

3D microfluidic hydrodynamic focusing is a potential candidate. It could regulate the distribution of the sample flow by introducing solutions from vertical and horizontal directions. ${ }^{37-39}$ It was applied for inhibiting ion diffusion ${ }^{40}$ and elevating the accuracy of $\mathrm{m} / \mathrm{z}$ in chip-MS platforms. ${ }^{11}$ If $3 \mathrm{D}$ hydrodynamic focusing is imposed to the sample flow, the total flow rate would increase to facilitate nESI with a FDM emitter, and mixing of sample and focusing solutions would also be inhibited. ${ }^{40}$

Herein, a nanoelectrospray ionization source (NIS), consisting of a 3D-printed nESI emitter, a housing case, and connecting components, was developed to achieve a 3D-printed nESI interface for chip-MS platforms. In order to facilitate nESI with a FDM emitter, 3D hydrodynamic focusing was applied to sample flows by imposing horizontal and vertical focusing flows. Moreover, heat drying nitrogen flows were applied to improve the nESI efficiency. In addition, NIS was used to probe organic chemicals and biological macromolecules after various 


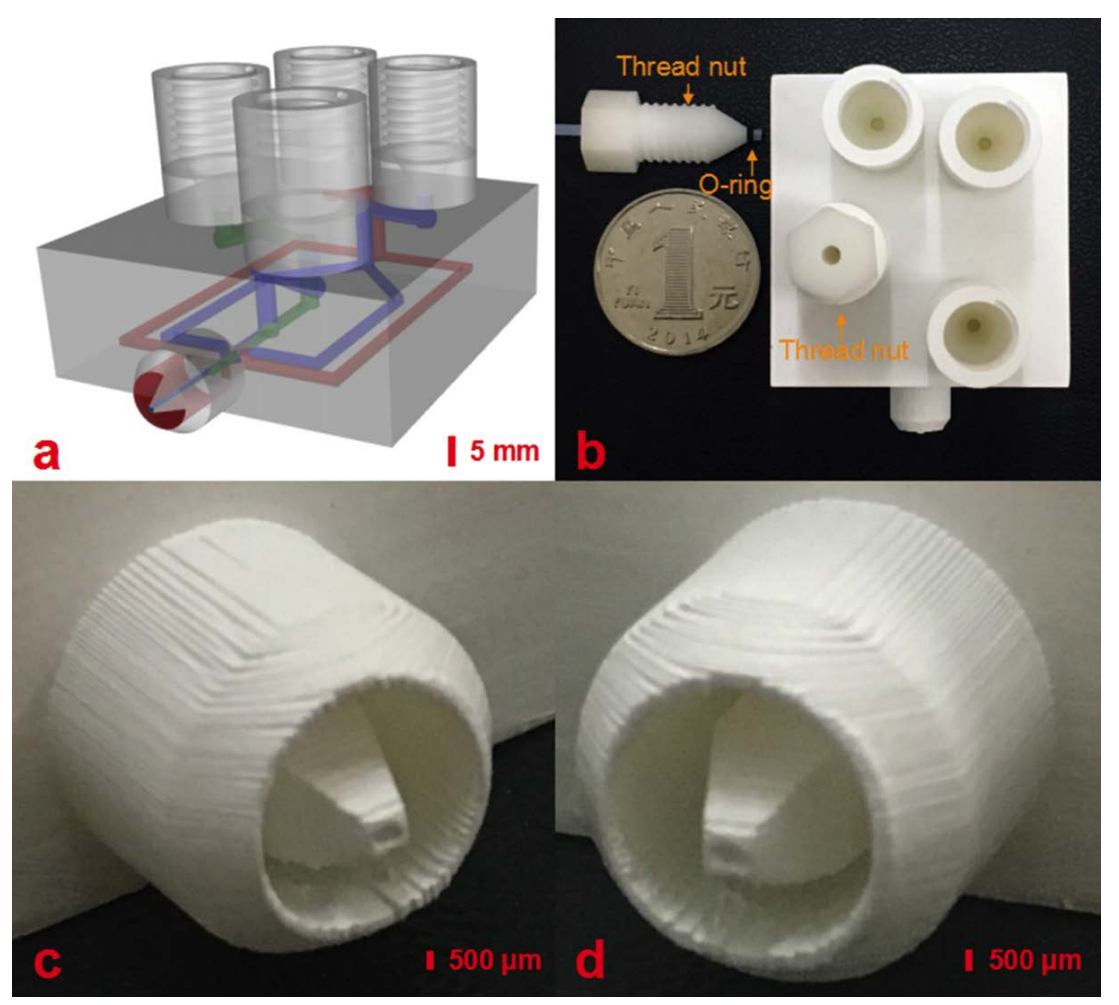

Fig. 1 3D-Printed nESI emitter in NIS. (a) Configuration of the nESI emitter, (b) its top-view photograph, a tubing assembled with a male thread nut and O-ring, and a thread nut fixed in the inlet, (c, d) side-view and front-view photographs of the nozzle in the nESI emitter.

optimizations. Finally, it was compatible with $50-500 \mathrm{~nL} \mathrm{~min}{ }^{-1}$ sample flows, and its sensitivities and linear ranges for different samples were investigated. The 3D-printed fabrication of NIS was facile (completely automatically) and low-cost (less than 35 USD). Therefore, the proposed method would be a standardized and user-friendly option to develop chip-MS platforms.

\section{Experimental}

\section{Reagents and chemicals}

The conductive focusing solution is mixture of methanol, double distilled water, and formic acid (80:19.9:0.1, v/v/v). Poly(lactic acid) (Print-Rite, Shenzhen, China) was used in all 3D-printed fabrications. Pyridalyl was from Prof. Guangfu Yang's group. Other chemicals including rhodamine $\mathrm{b}(\mathrm{RhB})$, chlorantraniliprole $(\mathrm{Chl})$, insulin from porcine pancreas and lysozyme were purchased from Sigma-Aldrich (St. Louis, USA), and all solvents were from Merck (Darmstadt, Germany).

\section{Fabrication of 3D-printed nESI emitter}

The nESI emitter (Fig. 1a) in NIS was designed with Rhinoceros 5.0 (Robert McNeel \& Associates, Seattle, USA). In the emitter, four female thread inlets and a $45^{\circ}$ apex nozzle were integrated to introduce various flows and to facilitate the electrospray, respectively. After converting the design into digital codes with software, Repetier Host (Print-Rite, Shenzhen, China), we used a CoLiDo 2.0 3D printer (Print-Rite, Shenzhen, China) to prepare the nESI emitter (Figs. $1 \mathrm{~b}-1 \mathrm{~d}$, approximately $41 \times 33 \times 17 \mathrm{~mm}$ ) with $100 \mu \mathrm{m}$ spatial precision and $99.9 \%$ filling density. 3D-Printed nuts with male threads (Fig. 1b) introduced tubings $(0.8 \mathrm{~mm}$ i.d., $1.6 \mathrm{~mm}$ o.d.) into inlets with female threads (Figs. 1a and 1b), and a rubber o-ring $(1.8 \mathrm{~mm}$ i.d., $4.0 \mathrm{~mm}$ o.d.) was used at the nut tip (Fig. 1b) to prevent leakages. The 3D configuration of the nESI emitter was presented with details in Supporting Information (Fig. S1). In the emitter, its opening size (the inner diameter) is $\sim 500 \mu \mathrm{m}$, and its wall thickness is $\sim 200 \mu \mathrm{m}$.

\section{Three dimensional hydrodynamic focusing}

After introducing from inlets (Figs. 1a and 2a), the sample flow (green) was wrapped by horizontal and vertical focusing flows (blue) in the emitter due to the laminar flow feature. A nitrogen flow (red) at room temperature was introduced as the nebulizer gas to facilitate the evaporation of various solutions (Figs. 1a and 2a). Auxiliary nitrogen was divided into two identical flows in the emitter (red, Fig. 1a), and converged into the cylindrical sheath tube around the spray nozzle.

\section{$3 D$-Printed NIS coupled with mass spectrometer}

The NIS was coupled with a 6224 TOF-MS (Agilent, Santa Clara, USA), as shown in the schematic configuration (Fig. 2a). Syringe pumps (Longer Pump, Baoding, China) infused different solutions into the 3D-printed nESI emitter. The auxiliary nebulizer nitrogen and the heat drying nitrogen were from a nitrogen generator (NM32LA, Peak Scientific, Ireland) and the TOF-MS, respectively. A platinum electrode was inserted in a T-shape adaptor to impose a voltage from a power supply (Dongwen, Tianjin, China) to the sample flow, and the other T-shape adaptor was used to introduce horizontal and vertical focusing flows into corresponding inlets.

A 3D-printed holder (Figs. 2b and 2c), cylindrical connecting tube (Fig. 2d), and plate connection bar (Fig. 2e) were developed to connect the proposed nESI emitter with a xyz regulator 


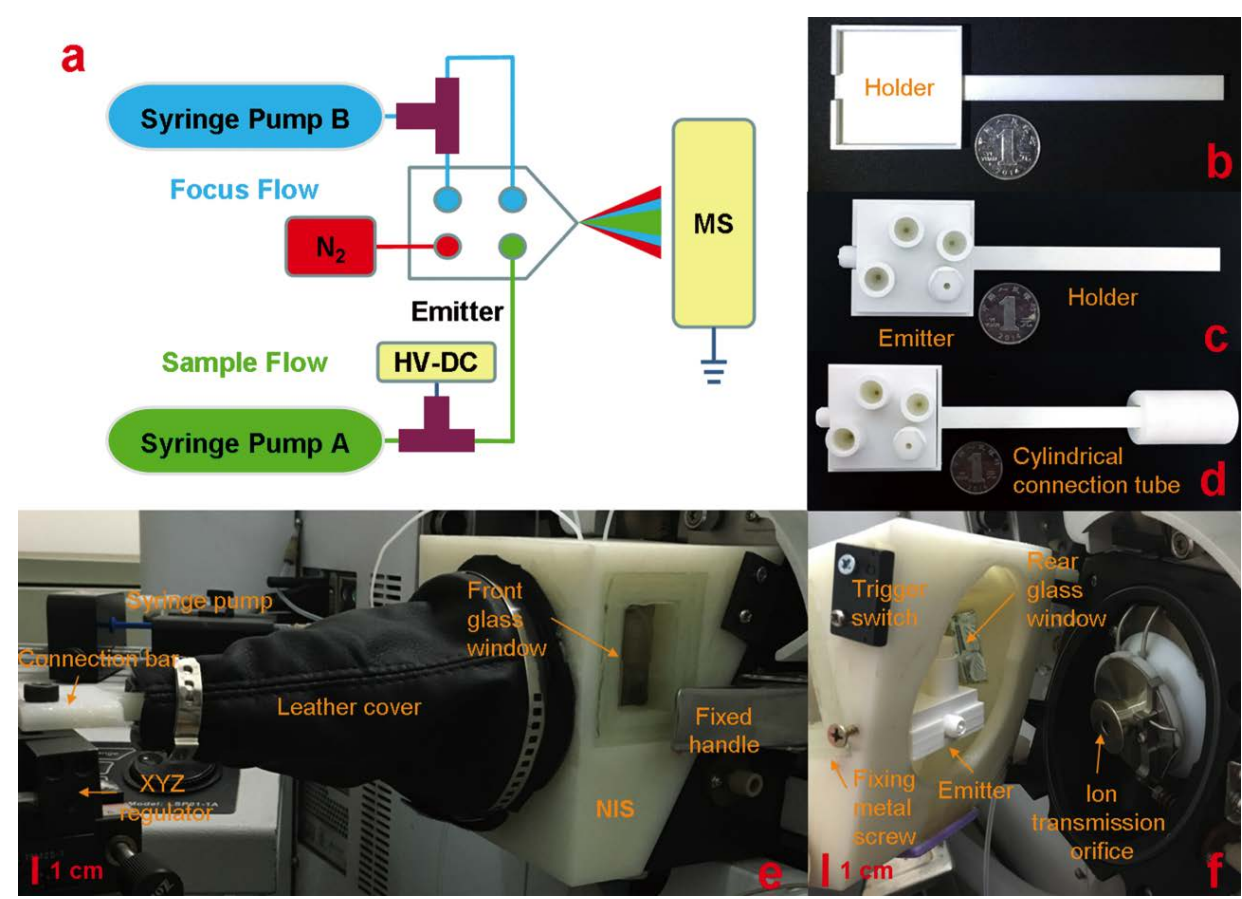

Fig. 2 3D-Printed NIS coupled with a TOF-MS. (a) Schematic configuration, (b, c) specific holder without and with the nESI emitter, (d) assembly consisting of the emitter, its holder and a cylindrical connection tube, (e) photograph of the NIS coupled with TOF-MS, (f) photograph of the nESI emitter in NIS.
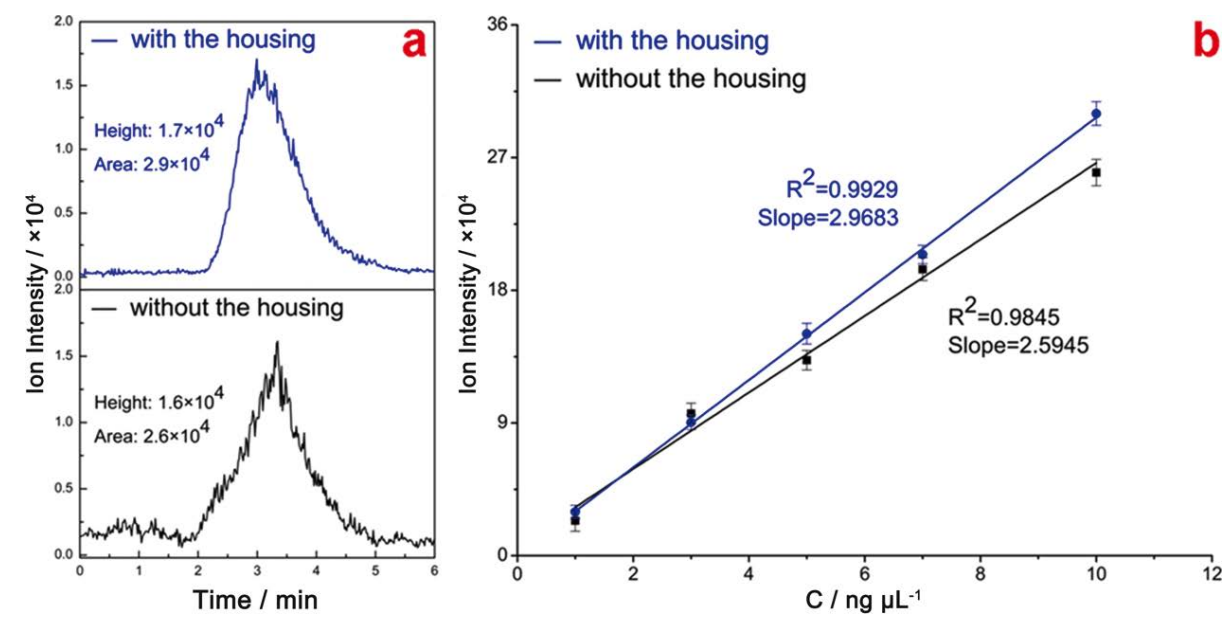

Fig. 3 Comparison of EICs for injecting $1.0 \mu \mathrm{L} \mathrm{RhB}$ solution with a $1 \mathrm{ng} \mu \mathrm{L}^{-1}$ concentration (a, $\mathrm{m} / \mathrm{z}$. 443.233) and linear calibration curves for $\mathrm{RhB}(\mathrm{b}, n=3)$ with and without the housing case in NIS. A $1500 \mathrm{~nL} \mathrm{~min}{ }^{-1}$ focusing flow and a $300 \mathrm{~nL} \mathrm{~min}{ }^{-1}$ sample flow were applied in all determinations.

(Fig. 2e). Additionally, a 3D-printed housing case (Fig. S2, Supporting Information, $134 \times 120 \times 82.0 \mathrm{~mm})$ and a leather cover were integrated in NIS (Fig. 2e) to inhibit the fluctuation of the ion current. Further, two glass windows, a metal screw for positioning and a trigger switch of the mass spectrometer were also integrated in the NIS (Fig. 2f). Prior to detections, the position of the nESI emitter relative to the ion inlet was optimized via obtaining the highest ion intensity for a standard chemical. A commercial nESI source (Agilent, Santa Clara, USA) was used as a commercial comparison to evaluate the NIS.

\section{Results and Discussion}

\section{Optimization of the NIS method}

Extracted ion profiles (EICs) for RhB were compared to assess the necessity of the housing case in NIS, and an improved stability was observed with its presence (Fig. 3a). Further, peak heights and areas in the EICs, the slopes of the linear calibration curves and their regression coefficients were better with the housing (Figs. 3a and 3b). The results shown in Fig. 3a indicated that the housing could alleviate fluctuation of the ion 

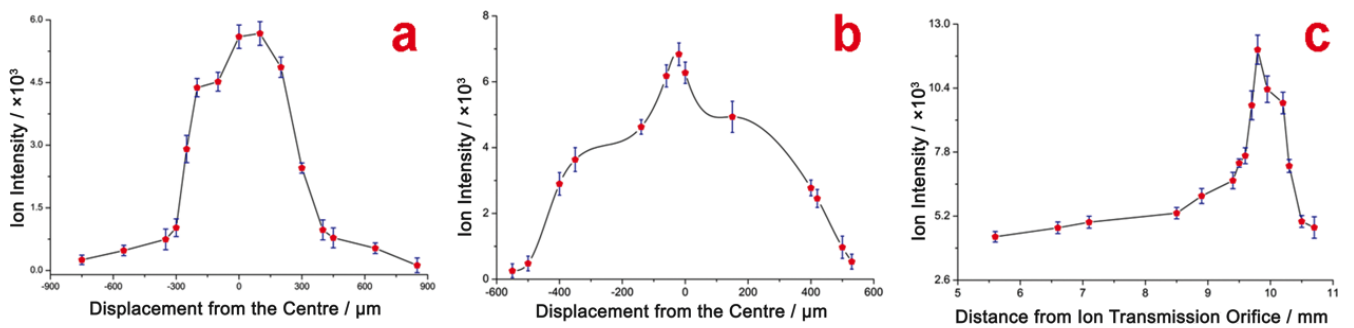

Fig. 4 Distribution of the $\mathrm{Chl}$ ion at different positions in the vertical (a), lateral (b) and radial (c) directions $(n=3)$. A $300 \mathrm{~nL} \mathrm{~min}{ }^{-1} \mathrm{Chl}$ solution $\left(5 \mathrm{ng} \mu \mathrm{L}^{-1}, \mathrm{~m} / z\right.$. 520.159) and a $1500 \mathrm{~nL} \mathrm{~min}{ }^{-1}$ focusing flow were applied in all determinations.

current. The detection limits of the NIS with and without its

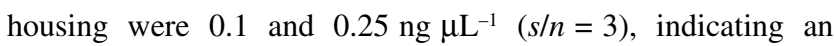
enhancement in the sensitivity. This would be because the adverse influence from random changes of the experimental environments (such as air flows) was inhibited, thus improving the stability and sensitivity of the NIS method.

The auxiliary nebulizer nitrogen in NIS was optimized by detecting Chl under different conditions. Two comparable maximum ion intensities of $\mathrm{Chl}$ were observed at 4.0 and $12.0 \mathrm{psi}$ auxiliary nitrogen pressure (Fig. S3a, Supporting Information). The change of the $\mathrm{Chl}$ ion intensity would be due to the increasing auxiliary nebulizer nitrogen, which facilitated generation of the aerosol plume and evaporation of the sample droplets with an auxiliary nebulizer nitrogen at $0-4.0$ and $10-14$ psi, respectively. Therefore, the sensitivity of the NIS method and the ion intensity of $\mathrm{Chl}$ improved with the nitrogen pressure within preceding two ranges. On the other hand, the increasing pressure $(0-50.0 \mathrm{psi})$ of the auxiliary nitrogen would also promote diffusion of the $\mathrm{Chl}$ ion, and reduce its ion intensities. Further, the ratio between the ion intensity of $\mathrm{Chl}$ and the total ion intensity, partially indicating the signal-tonoise ratio $(s / n)$, was better at $12.0 \mathrm{psi}$ compared with its counterpart at $4.0 \mathrm{psi}$ (Fig. S3b, Supporting Information). At last, the aerosol plume was more stable with 12.0 psi auxiliary nitrogen, and this condition was thus applied in the proposed NIS method.

The maximum ion intensity of $\mathrm{Chl}$ was obtained with a $310^{\circ} \mathrm{C}$ drying nitrogen from the ion transmission orifice (Fig. S3c, Supporting Information). When the temperature was lower than $300^{\circ} \mathrm{C}$, the ion intensity fluctuated due to slow evaporation of the sample droplets. Further, the drying gas at $310^{\circ} \mathrm{C}$ melted the 3D-printed nESI nozzle when its flow rate was greater than 1.5 $\mathrm{L} \mathrm{min}^{-1}$, despite that greater flow rates $\left(1.5-3.6 \mathrm{~L} \mathrm{~min}^{-1}\right)$ enhanced the ion intensity (Fig. S3d, Supporting Information). The drying nitrogen flow was thus applied at $310^{\circ} \mathrm{C}$ and $1.5 \mathrm{~L} \mathrm{~min}^{-1}$.

Finally, the relative standard deviations (RSDs) of the total ion current (TIC) profiles were investigated at different ionization voltages, and an optimal stability was observed at $5.0 \mathrm{kV}$ (Fig. S4, Supporting Information). The ion intensity became more stable when the voltage increased from 2.0 to $5.0 \mathrm{kV}$. This would probably be because the increasing voltage magnified the charge density in the sample droplets, thus improving their splitting in the nESI process. On the contrary, this trend was reversed when the voltage was within 5.0$7.0 \mathrm{kV}$, this would be because the excessive voltage would lead to electric discharges, which caused the generation of extraneous ions and additional fluctuations of the ion current. Therefore, an optimal $5.0 \mathrm{kV}$ voltage was applied in NIS, being greater than previous reports. ${ }^{41,42}$ This discrepancy would be because
Table 1 Detected molecular ions of various organic chemicals and their $\mathrm{m} / \mathrm{z}$

\begin{tabular}{|c|c|c|c|c|}
\hline \multirow{2}{*}{ Chemical $^{\text {a }}$} & \multirow{2}{*}{ omposition } & & \multicolumn{2}{|c|}{$\mathrm{m} / \mathrm{z}$} \\
\hline & & & Detected & Theoretical \\
\hline zoxyst & $\mathrm{C}_{22} \mathrm{H}_{17} \mathrm{~N}_{3} \mathrm{O}_{5}$ & $(\mathrm{M}+\mathrm{K})^{+}$ & 442.1484 & 442.0800 \\
\hline Bentazone & $\mathrm{C}_{10} \mathrm{H}_{12} \mathrm{~N}_{2} \mathrm{O}_{3} \mathrm{~S}$ & $\mathrm{M}+\mathrm{K})^{+}$ & 279.0472 & 279.0200 \\
\hline Chl & $\mathrm{C}_{18} \mathrm{H}_{14} \mathrm{~N}_{5} \mathrm{O}_{2} \mathrm{Cl}_{2} \mathrm{Br}$ & $(\mathrm{M}+\mathrm{K})^{+}$ & 520.1598 & 519.9340 \\
\hline $\begin{array}{l}\text { Dichlorobenzoic } \\
\text { acid }\end{array}$ & $\mathrm{C}_{7} \mathrm{H}_{5} \mathrm{O}_{2} \mathrm{Cl}$ & $(\mathrm{M}+\mathrm{K})^{+}$ & 194.6723 & 194.9610 \\
\hline Difenoconazole & $\mathrm{C}_{19} \mathrm{H}_{17} \mathrm{~N}_{3} \mathrm{O}_{3} \mathrm{Cl}_{2}$ & $\mathrm{M}+\mathrm{H})^{+}$ & 745 & 720 \\
\hline $\begin{array}{l}\text { Emamectin } \\
\text { benzoate }\end{array}$ & $\mathrm{C}_{56} \mathrm{H}_{81} \mathrm{NO}_{15}$ & $(\mathrm{M}+\mathrm{H})^{+}$ & 1008.5086 & 1008.5679 \\
\hline Hexaconazole & $\mathrm{C}_{14} \mathrm{H}_{17} \mathrm{~N}_{3} \mathrm{O} \mathrm{Cl}_{2}$ & 101 & 11 & 313 \\
\hline arathio & $\mathrm{C}_{8} \mathrm{H}_{10} \mathrm{I}$ & $(\mathrm{M}+\mathrm{H}$ & 94 & 264.0090 \\
\hline Propiconazole & $\mathrm{C}_{15} \mathrm{H}_{17} \mathrm{~N}_{3} \mathrm{O}_{2} \mathrm{Cl}_{2}$ & $\mathrm{M}^{+}$ & 341.0711 & 341.0692 \\
\hline Pyridalyl & $\mathrm{C}_{18} \mathrm{H}_{14} \mathrm{NO}_{3} \mathrm{~F}_{3} \mathrm{Cl}_{4}$ & $(\mathrm{M}+\mathrm{H})^{+}$ & 489.9900 & 489.9753 \\
\hline $\mathrm{hhB}$ & $\mathrm{C}_{28} \mathrm{H}_{31} \mathrm{~N}_{2} \mathrm{O}_{3} \mathrm{Cl}$ & $(\mathrm{M}-\mathrm{Cl})^{+}$ & 443.2333 & 443.2329 \\
\hline Tebuconazole & $\mathrm{C}_{16} \mathrm{H}_{22} \mathrm{~N}_{3} \mathrm{OCl}$ & $(\mathrm{M}+\mathrm{H})^{+}$ & 308.2512 & 308.1524 \\
\hline
\end{tabular}

a. Sample flows $\left(0.5 \mathrm{ng} \mu \mathrm{L}^{-1}, 300 \mathrm{~nL} \mathrm{~min}^{-1}\right)$ and the focusing flow $\left(1500 \mathrm{~nL} \mathrm{~min}^{-1}\right)$ were applied in all determinations.

the voltage in NIS was applied on the sample flow, which was distant from the nESI nozzle, and the nozzle of the 3D-printed emitter had a relatively large diameter.

\section{Distribution of the sample ion}

In order to study the configuration of the nanoelectrospray in NIS, we investigated the spatial distribution of the sample ion in the spray from the 3D-printed nESI emitter. Firstly, the $\mathrm{Chl}$ ion gathered in the central region of both the lateral and vertical directions (Figs. 4a and 4b). Further, the ion intensities at 0 - $200 \mu \mathrm{m}$ upward displacements from the center were greater than their counterparts at downward displacements (Fig. 4a), while this trend was absent in the lateral direction (Fig. 4b). The asymmetrical distribution in the vertical direction would probably be due to unsymmetrical vertical hydrodynamic focusing for the sample flow in the 3D-printed emitter (Fig. 1a). Meanwhile, the ion intensities were symmetric in the lateral direction, which implied symmetric lateral focusing for the sample flow in NIS. Preceding results demonstrated that the conical configuration of the electrospray in NIS was retained with the presence of both nebulizer and drying nitrogen flows, both of which distributed symmetrically around the nESI nozzle. Otherwise, either the asymmetrical distribution of the $\mathrm{Chl}$ ion in the vertical direction (Fig. 4a) or its symmetrical distribution in the lateral direction (Fig. 4b) would not remain.

The ion intensities of $\mathrm{Chl}$ at different radial positions were investigated to optimize the distance between the nESI nozzle and the ion transmission orifice (Fig. 4c). The maximum 

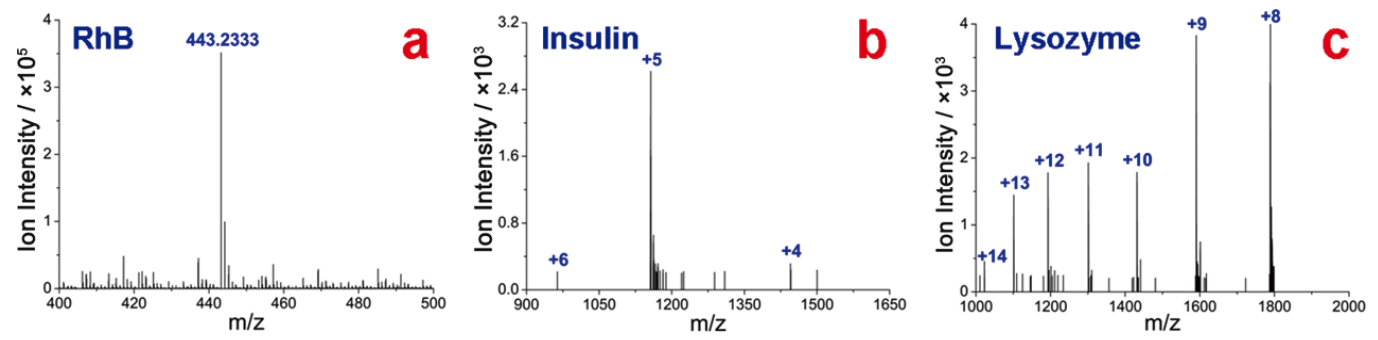

Fig. 5 Mass spectra of $\mathrm{RhB}\left(\mathrm{a}, 0.5 \mathrm{ng} \mu \mathrm{L}^{-1}\right.$ ), insulin (b, $\left.30 \mathrm{ng} \mu \mathrm{L}^{-1}\right)$ and lysozyme (c, $50 \mathrm{ng} \mu \mathrm{L}^{-1}$ ) with the 3D-printed NIS. The infusion rates of the sample and focusing flows were all 300 and $1500 \mathrm{~nL} \mathrm{~min}^{-1}$.

intensity was obtained at $9.8 \mathrm{~mm}$. Its intensity was negligible when the distance was less than $9.0 \mathrm{~mm}$ or more than $10.5 \mathrm{~mm}$. This would be because the nESI of Chl was inadequate at distances less than $9.0 \mathrm{~mm}$, and its diffusion would be too serious at greater distances than $10.5 \mathrm{~mm}$.

\section{Applications and evaluations of the NIS}

The NIS was applied to detect thirteen organic chemicals $\left(0.5 \mu \mathrm{g} \mathrm{mL}^{-1}\right)$, and their molecular ions as well as corresponding $m / z$ were presented in Table 1 . This indicates that the NIS achieved nESI MS identifications for various samples with molecular ions at $194.67-1008.51 \mathrm{~m} / \mathrm{z}$ and with an accuracy of $\mathrm{m} / \mathrm{z}$, between $9.02 \times 10^{-1}$ and $1.48 \times 10^{3} \mathrm{ppm}$. Additionally, the $s / n$ in all determinations was better than 4.9 , and the $s / n$ for $\mathrm{RhB}$ $\left(0.5 \mu \mathrm{g} \mathrm{mL}^{-1}\right)$ was 8.4 (Fig. 5a). In order to investigate the feasibility to probe negative ions with NIS, it was applied to detect hydrocortisone and vitamin $\mathrm{C}$, and their negative molecular ions were observed as $\mathrm{m} / \mathrm{z}, 407.4381$ and 175.2362 corresponding to $[\mathrm{M}+\mathrm{COOH}]^{-}$and $[\mathrm{M}-\mathrm{H}]^{-}$, respectively. Additionally, the $[\mathrm{M}-\mathrm{H}]^{-}$and $[\mathrm{M}+\mathrm{H}]^{+}$ions of hydrocortisone were also observed at $\mathrm{m} / \mathrm{z}, 361.3619$ and 363.0289 in its mass spectra under both positive and negative ionizations (Fig. S5, Supporting Information).

Additionally, the NIS was also used to probe biological macromolecules, insulin and lysozyme, and their multiple charged ions were observed in their MS spectra (Figs. 5b and 5c). With preceding determinations, the deconvoluted molecular weights of insulin and lysozyme were 5777.13 and 14307.62 with the NIS. With a commercial nESI source as a comparison, their molecular weights were 5776.56 and 14306.53, and the relative mass deviations with the NIS and the commercial nESI source were 98.7 and $76.2 \mathrm{ppm}$ for insulin and lysozyme. Preceding mass deviations would be due to an absence of the real-time mass calibration in the NIS. It was also used to detect BSA, and series of ions within $\mathrm{m} / \mathrm{z} 1100$ - 1900 were identified with $36-59$ positive charges, based on which their molecular weight was deconvoluted as $66.5 \mathrm{kDa}$.

The limit of detection $(s / n=3)$ with the NIS was 0.1 and $0.4 \mu \mathrm{g} \mathrm{mL}^{-1}$ for $\mathrm{RhB}$ and pyridalyl, respectively. As a comparison, $\mathrm{RhB}$ and pyridalyl were determined by a commercial nESI source, whose limits of detection $(s / n=3)$ were 0.04 and $0.24 \mu \mathrm{g} \mathrm{mL}^{-1}$ for $\mathrm{RhB}$ and pyridalyl. The detection limit of the 3D-printed NIS was slightly worse than their counterparts with the commercial nESI source. There may be two reasons for this. Firstly, the background ions from the dissolved PLA in methanol would deteriorate the detection limit of the NIS. Although the PLA used in the 3D printing appeared in the MS spectra as background ions, its adverse influence could be partly eliminated by deducing the background spectrum, which would be solved by using polystyrene instead of PLA. Additionally, the total flow rates in NIS were five times their counterparts in the commercial source, which depressed the sensitivity of the NIS.

The linear ranges of the NIS were $1-10 \mathrm{ng} \mu \mathrm{L}^{-1}\left(R^{2}=0.9929\right.$, Fig. 3b) and $0.5-8 n g \mu \mathrm{L}^{-1}\left(R^{2}=0.9694\right.$, Fig. S6, Supporting Information) for $\mathrm{RhB}$ and pyridalyl, respectively. Preceding sensitivities and linear ranges were attributed to the TOF mass analyzer, which was insufficient in sensitivity and quantification. The sensitivities and linear ranges of the NIS method would be improved by using a tandem mass analyzer.

Focusing flows with methanol, acetonitrile and ammonium formate were compared as the conductive focusing solutions, and their RSDs of total ion current (TIC) profiles lasting for 4 min were $7.2,19.3$ and $43.7 \%$. There were more background ions when using ammonium formate compared with its counterparts when using formic acid, and this may be related to the instability of ammonium ions in the nESI process. The molecular ions of dimethoate were probed when applying different focusing solutions (Fig. S7, Supporting Information). Overall, we could obtain more stable total ion current (TIC) profiles with the NIS when using a mixture of methanol, water and formic acid, although acetonitrile and ammonium formate could also be used in the conductive focusing solutions.

Finally, the compatible flow rate of the NIS was evaluated, and it could identify $\mathrm{RhB}$ within $50-500 \mathrm{~nL} \mathrm{~min}^{-1}$ (Fig. 6). The RSD of the total ion current (TIC) profiles deteriorated when the sample flow rate increased from 300 to $500 \mathrm{~nL} \mathrm{~min}{ }^{-1}$, and the electrospray is intermittent when the flow rate is beyond $500 \mathrm{~nL} \mathrm{~min}{ }^{-1}$. This would be because the NIS could not provide an adequate charge density to the sample droplets or result in an inappropriate evaporation of the solvent when the flow rate was too great. Moreover, the RSD of total ion current (TIC) profiles improved when the sample flow rate increased from 150 to $300 \mathrm{~nL} \mathrm{~min}{ }^{-1}$, and the best RSD for the total ion intensity lasting for $4 \mathrm{~min}, 7.2 \%$, was achieved with a $300 \mathrm{~nL} \mathrm{~min}{ }^{-1}$ flow rate (Fig. 6). This may be because the hydrodynamic focusing in the 3D-printed emitter was more stable at a greater sample flow rate within $150-300 \mathrm{~nL} \mathrm{~min}{ }^{-1}$, thus improving the stability of the nESI process. As a comparison, the commercial nESI source achieved a $3.1 \%$ RSD, and its improved stability would be because of its better stability of the pressure to drive solutions and more straight-forward configuration to impose voltages.

Further, the RSD of the total ion current (TIC) profiles became worse when the sample flow rate increased from 50 to $150 \mathrm{~nL}$ $\min ^{-1}$ (Fig. 6), and the NIS achieved superior sensitivity and signal stability with a smaller sample flow rate at $50-150 \mathrm{~nL}$ $\mathrm{min}^{-1}$. This may be because the sample droplets in electrospray aerosol plume had a smaller size compared with its counterparts when applying greater flow rates, and their relatively smaller sizes promoted the dispersion, volatilization and ionization of sample solutions, thus resulting in a slightly enhanced nESI stability at $50 \mathrm{~nL} \mathrm{~min}{ }^{-1}$ (Fig. 6). Stable MS detections with the 


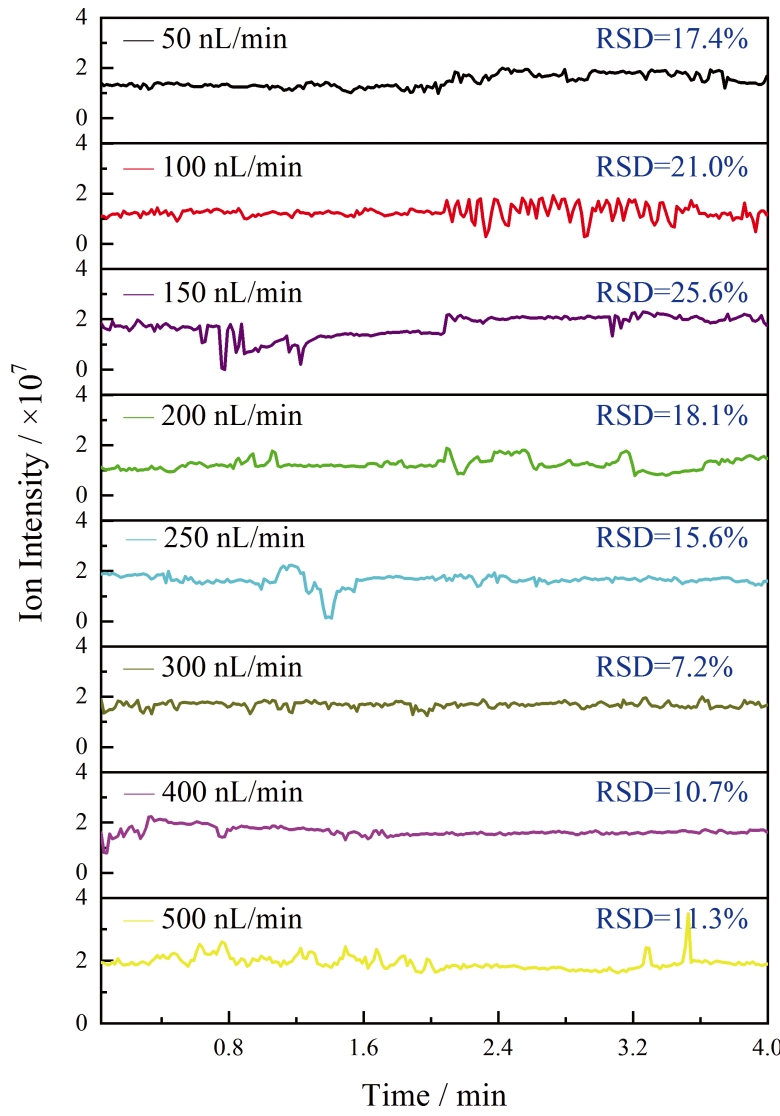

Fig. 6 Comparison of the total ion current (TIC) profiles and RSDs at different flow rates of $\mathrm{RhB}$. The $\mathrm{RhB}$ solution $\left(5 \mathrm{ng} \mathrm{\mu L}^{-1}\right)$ and a focusing solution $\left(1.5 \mathrm{ng} \mu \mathrm{L}^{-1}\right)$ were applied in all determinations.

NIS were not feasible when the sample flow rate was less than $50 \mathrm{~nL} \mathrm{~min}^{-1}$, which may be because the total flow rate was too low to maintain a stable nESI. If a bypass is added to split the flow phase, the prosed NIS would also be connected with conventional LC columns working with a $0.2-1.0 \mathrm{~mL} \mathrm{~min}^{-1}$ flow rate, although their separation efficiencies would not completely remain due to the broadening.

\section{Conclusions}

We developed a facile and automatic 3D-printing method to prepare monolithic nESI emitters in microfluidic chips and to achieve nESI MS detections for sample flows. Firstly, the housing in NIS was capable in inhibiting ion intensity fluctuations due to environmental changes, thus improving the sensitivity of the proposed method. Additionally, the spatial distribution of the sample ion supported compensation for the total flow rate and inhibition for ion expansion via the 3D hydrodynamic focusing in NIS. Moreover, the NIS could identify thirteen organic chemicals and biological macromolecules, insulin and lysozyme. The quantitative linear ranges and limits of detection of the NIS were investigated, indicating comparable performances compared with a commercial nESI source. Finally, the NIS was compatible with

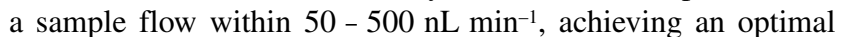
$7.2 \%$ RSD of the total ion current (TIC) profiles at $300 \mathrm{~nL}$ $\mathrm{min}^{-1}$. Considering the 3D-printing preparation of NIS is userfriendly and low-cost (less than 7 and 35 USD), the proposed method would be not only an option to fabricate monolithic nESI interface in microfluidic chips, but also a potential strategy to develop customized nESI-MS platforms. Considering the progress of 3D printing, it would also be a foreseeable option to prepare the NIS with metal-based 3D printing technology, which would provide an improved resolution.

\section{Acknowledgements}

Mrs. Yinyin Hao and Ms. Xing Su in SCUEC and CCNU are appreciated for their revisions in English usage. Prof. Guangfu Yang in CCNU is appreciated to provide pyridalyl. This research was financially supported by the program of introducing talents of discipline to universities of China (111 Program, B17019), self-determined research funds of CCNU from the colleges' basic research and operation of MOE (CCNU19KYZHSY07, CCNU19TS053).

\section{Supporting Information}

The configuration of the housing case, $\mathrm{Chl}$ ion intensities at different auxiliary and drying nitrogen conditions, the RSDs of the total ion intensities at different voltages, mass spectra of hydrocortisone under positive and negative ionizations, the linear curve for pyridalyl, and mass spectra of dimethoate when using different focusing flows were in the supporting information. This material is available free of charge on the Web at http://www.jsac.or.jp/analsci/.

\section{References}

1. M. R. Emmett and R. M. Caprioli, J. Am. Soc. Mass. Spectrom., 1994, 5, 605.

2. M. Wilm and M. Mann, Anal. Chem., 1996, 68, 1.

3. A. J. Chetwynd and A. David, Talanta, 2018, 182, 380.

4. M. Rahman, D. Wu, and K. Chingin, J. Am. Soc. Mass. Spectrom., 2019, 30, 814.

5. K. Zheng, J. E. Lesniewski, M. J. Dolan, Jr., W. Li, T. T. Metallo, and K. Jorabchi, Anal. Chem., 2020, 92, 10129.

6. X. Sun, R. T. Kelly, K. Tang, and R. D. Smith, Analyst, 2010, 135, 2296.

7. X. Zhong, L. Qiao, G. Stauffer, B. Liu, and H. H. Girault, J. Am. Soc. Mass. Spectrom., 2018, 29, 1538.

8. T. Sikanen, S. Franssila, T. J. Kauppila, R. Kostiainen, T. Kotiaho, and R. A. Ketola, Mass Spectrom. Rev., 2010, 29, 351.

9. X. W. He, Q. S. Chen, Y. D. Zhang, and J. M. Lin, TrAC, Trends Anal. Chem., 2014, 53, 84.

10. X. Sun, R. T. Kelly, K. Tang, and R. D. Smith, Anal. Chem., 2011, 83, 5797.

11. L. Wang, Y. Wang, S. Jiang, M. Ye, P. Su, and B. Xiong, J. Chromatogr. A, 2016, 1470, 1.

12. M. F. Bedair and R. D. Oleschuk, Anal. Chem., 2006, 78, 1130.

13. L. Sainiemi, T. Nissila, R. Kostiainen, S. Franssila, and R. A. Ketola, Lab Chip, 2012, 12, 325.

14. R. T. Kelly, J. S. Page, Q. Luo, R. J. Moore, D. J. Orton, K. Tang, and R. D. Smith, Anal. Chem., 2006, 78, 7796.

15. M. Wilm and M. Mann, Anal. Chem., 1996, 68, 1.

16. D.-Q. Jin, Y. Zhu, and Q. Fang, Anal. Chem., 2014, 86, 10796.

17. C. Lotter, J. J. Heiland, S. Thurmann, L. Mauritz, and D. 
Belder, Anal. Chem., 2016, 88, 2856.

18. R. F. Gerhardt, A. J. Peretzki, S. K. Piendl, and D. Belder, Anal. Chem., 2017, 89, 13030.

19. Y. Lu, F. Liu, N. Lion, and H. H. Girault, J. Am. Soc. Mass. Spectrom., 2013, 24, 454.

20. P. Hoffmann, M. Eschner, S. Fritzsche, and D. Belder, Anal. Chem., 2009, 81, 7256.

21. M. Prudent, M. A. Mendez, and H. H. Girault, Anal. Sci., 2008, 24, 1399.

22. M. Prudent, M. A. Mendez, C. Roussel, B. Su, N. Lion, J. S. Rossier, and H. H. Girault, Chimia, 2009, 63, 283.

23. T. Yamashita, K. Yasukawa, and E. Yunoki, Anal. Sci., 2019, 35, 769 .

24. M. Groesche, A. E. Zoheir, J. Stegmaier, R. Mikut, D. Mager, J. G. Korvink, K. S. Rabe, and C. M. Niemeyer, Small, 2019, 15, 1901956.

25. G. I. J. Salentijn, P. E. Oomen, M. Grajewski, and E. Verpoorte, Anal. Chem., 2017, 89, 7053.

26. F. Li, N. P. Macdonald, R. M. Guijt, and M. C. Breadmore, Anal. Chem., 2017, 89, 12805.

27. F. Cecil, R. M. Guijt, A. D. Henderson, M. Macka, and M. C. Breadmore, Anal. Chim. Acta, 2020, 1097, 127.

28. E. M. Richter, D. P. Rocha, R. M. Cardoso, E. M. Keefe, C. W. Foster, R. A. Munoz, and C. E. Banks, Anal. Chem., 2019, 91, 12844

29. G. I. J. Salentijn, R. D. Oleschuk, and E. Verpoorte, Anal. Chem., 2017, 89, 11419.
30. G. I. J. Salentijn, H. P. Permentier, and E. Verpoorte, Anal. Chem., 2014, 86, 11657.

31. A. Hollerbach, Z. Baird, and R. G. Cooks, Anal. Chem., 2017, 89, 5058.

32. A. Hollerbach, P. W. Fedick, and R. G. Cooks, Anal. Chem., 2018, 90, 13265.

33. E. M. Tridas, C. Allemang, F. Mast, J. M. Anthony, and R. Schlaf, J. Mass Spectrom., 2015, 50, 938.

34. V. Geertsen, E. Barruet, and O. Tache, J. Anal. At. Spectrom., 2015, 30, 1369.

35. C. K. Su, S. C. Hsia, and Y. C. Sun, Anal. Chim. Acta, 2014, $838,58$.

36. P. Sosnowski and G. Hopfgartner, Talanta, 2020, 215, 120894.

37. M. A. Daniele, D. A. Boyd, D. R. Mott, and F. S. Ligler, Biosens. Bioelectron., 2015, 67, 25.

38. P. Sajeesh, S. Manasi, M. Doble, and A. K. Sen, Lab Chip, 2015, 15, 3738.

39. M. Lu, S. Yang, Y. P. Ho, C. L. Grigsby, K. W. Leong, and T. J. Huang, Acs Nano, 2014, 8, 10026.

40. B. Xiong, L. Wang, Y. Wang, Y. Bao, S. Jiang, and M. Ye, Analyst, 2016, 141, 177.

41. Q. Fu, J. Tang, M. Cui, Z. Zheng, Z. Liu, and S. Liu, J. Chromatogr. B, 2015, 990, 169.

42. X. F. Sun, R. T. Kelly, K. Q. Tang, and R. D. Smith, Anal. Chem., 2011, 83, 5797 . 